\title{
Management of aortic graft infections - the present strategy and future perspectives
}

\author{
Treska V, Certik B, Molacek J \\ Department of Surgery, Charles University Hospital, School of Medicine, Pilsen, Czech Republic. \\ treska@fnplzen.cz
}

\begin{abstract}
Aortic graft infections (AGI) are serious complications of open and endovascular types of surgery with an incidence rate of $0.6-3 \%$. AGI are associated with 30-60\% perioperative mortality and $40-60 \%$ morbidity rate with limb amputation rates between $10 \%$ and $40 \%$. The economic cost of AGI is substantial. At the time of aortic reconstruction, almost $90 \%$ of patients have one or more predisposing factors for AGI. The diagnosis is based on clinical symptomatology, laboratory markers, microbial cultures, and imaging modalities. The general principle of surgical treatment lies in the removal of infected graft, debridement of infected periprosthetic tissues, and vascular reconstruction by in situ or extra-anatomic bypass with long-term antibiotic therapy. The conservative treatment is used only for selected patients with endograft infection. This review summarizes the current knowledge about the incidence, predisposing factors, etiology, diagnosis, treatment options, and prevention of aortic vascular graft and endograft infections. With the growing number of endovascular procedures we can expect more cases of infected aortic endografts in patients with severe comorbidities in the near future, where the recent radical surgical approach (graft excision, debridement, and new revascularization) cannot be used. Therefore the less invasive, sophisticated and individualized treatment strategies will have to be used in search of the best therapeutic approach to each specific patient (Fig. 4, Ref. 82). Text in PDF www.elis.sk. KEY WORDS: aortic graft infections, incidence, etiology, management, treatment perspectives.
\end{abstract}

\section{Introduction}

Aortic graft infections (AGI) are very serious complications of arterial reconstructive surgery. AGI are defined as an infection of any vascular and endovascular grafts implanted from subdiaphragmatic aorta to the groin. The typical AGI are the infections of aortobifemoral reconstructions or endografts. The incidence of AGI is reported between $0.6-3 \%$. Whereas 20 years ago the only problem used to be the infection of aortic graft reconstruction after open surgery, recently we have been witnessing the growing incidence of endograft infections after endovascular aneurysm repair (EVAR). The average frequency of EVAR infection is estimated at $0.5-0.7 \%$. AGI are very often a catastrophic event for the patients and are associated with $30-60 \%$ perioperative mortality rate and 40-60 \% morbidity rate with limb amputation rates from 10 to $40 \%$. AGI lead to a prolonged hospital stay, long-term inability to work, significant incidence of graft reinfections and hospital readmissions. The economic costs of AGI are substantial. The

Department of Surgery, Charles University Hospital, School of Medicine, Pilsen, Czech Republic

Address for correspondence: V. Treska, MD, PhD, Department of Surgery, Charles University Hospital, School of Medicine, Husova 3, CZ-320 00 Pilsen, Czech Republic.

Phone: +420.37.710 4270, Fax: +420.37.7103945

Acknowledgement: The article was supported by the Research Project of Charles University in Prague, P 36. approximate cost of treatment of single AGI episode is estimated at 40-50,000 US dollars $(1,2)$.

\section{Risk factors}

Predisposing factors to AGI are redo- and emergency surgeries, prolonged operative time (which increases the incidence of graft infection 2-3 times), nasal carriage of Staphylococcus species, perioperative infection in another site, older age, female gender, critical limb ischemia, obesity and overweight, chronic obstructive pulmonary disease, malnutrition and hyperglycemia, operative time prolonged over four hours, inadequate type of antibiotics and time of their perioperative application, breaks in sterile technique with contamination, hematogenous seeding during bacteremia and retractor-related tissue trauma. Also interventional radiology suites dispose of lower level of sterility and greater chance of endograft contamination. Surgical site of infection (SSI) is the cause of AGI in $4-40 \%$ of cases. The relationship between female gender, obesity, and higher incidence of graft infection includes gender-related differences in the amount and distribution of poorly vascularized body fat and differences in native skin flora especially in the groin area. Altered levels of leptin and adiponectin in obese patients contribute to proinflammatory states and predispose to infection. End-stage renal disease is a well-known risk factor for AGI. Uremia acts as a depression of the immune system and patients on hemodialysis have higher rates of colonization by staphylococci including methicillin-resistant Staphylococcus aureus. Another pre- 
dictive factor showed by experimental research is lower bacterial resistance and greater bacterial adherence to endovascular devices. Animal models showed a higher concentration of bacteria in endovascular (mainly PTFE) grafts than in grafts used in open surgery (3). Another risk factor is the thrombus infection of abdominal aneurysm which is routinely cultured in $5 \%$ of patients during elective open aneurysm repair. Immunodeficiency, i.e. corticosteroid therapy lasting longer than theee months is also associated with higher AGI. Implantation of various stent grafts in a radiological suite can be a potential risk factor of AGI. Secondary interventions, which are more common after EVAR procedures, increase significantly the AGI rate and cause approximately $25 \%$ of infections after EVAR (4). Contact of suture line, vascular prosthesis or endovascular anchors with bowel (usually duodenum), and endograft migration or its severe angulation can lead in the longer postoperative period to the development of aorto-enteric fistula (AEF). At the time of vascular reconstruction, almost $90 \%$ of patients have one or more factors predisposing to graft infection $(5,6)$.

\section{Prevention}

All the above-mentioned factors predisposing to AGI are also the main targets for strong prevention of AGI. Systemic prophylactic antibiotics (first or second generation of cephalosporin) with the first application 30-60 minutes before skin incision are strong protective means which significantly reduce the AGI rate. The second dosage of antibiotics is usually given after 120 minutes. Antibiotic prophylaxis longer than 24 hours does not have any additional benefit. Daptomycin or vancomycin should be administered adjunctively in a patient known to be a carrier of MRSA. Prophylactic antibiotics should be used in patients with aortic grafts where the risk of bacteremia is present, such as dental and endoscopic procedures. Topic antibiotics have not been studied in vascular surgery in general; collagen implant with gentamicin sulphate has shown a reduction in surgical site of infection in cardiac, orthopedic and general surgical procedures. Almeida (7) showed that topic application of collagen implant with gentamicine sulphate, which is active against Staphylococcus and gram-negative germs, significantly reduced SSI and additional usage of collagen as a carrier had an effect on healing and hemostasis. Prophylactic use of antibiotic bounding or silver-coated grafts has no effect in the prevention of AGI (8).

\section{Classification}

AGI is classified by various systems proposed by various authors. The basic classification is done according to the time of development and severity of infection. Early AGI is an infection coming within four months after the vascular procedure and is the most common (in $60-80 \%$ of cases). Late AGI comes four months after the vascular reconstruction. Low-grade infections occur later and are caused by low-virulence bacteria. High-grade infections come earlier after the primary vascular reconstruction and are caused by more aggressive microorganisms. The oldest, simplest, and still very useful classification is the Szilagy's classification invented in 1972. Grade I is phlegmone, grade II is subcutaneous tissue infection, and grade III is graft infection. Very similar, clinically effective classification is also Samson's classification: grade 1 is superficial infection involving the skin and/or subcutaneous tissue; grade 2 is deep incisional infection involving deep soft tissues such as fascia and muscles; grade 3 is infection without anastomosis site involvement; grade 4 is infection with anastomosis involvement and grade 5 is infection with anastomotic disruption. Another classification of graft infection is that by Goeau-Brissonniere based on the results of bacterial culture, histological sampling, and time of presentation $(9,10,11)$.

\section{Pathogenesis}

Prosthetic grafts are colonized by microorganisms via direct invasion or via hematogenous seeding. Microorganisms produce biofilms, a polymeric matrix, which adheres to artificial surface of vascular grafts and enables the growth of microorganisms with high resistance to the host immune system and antibiotics. Although many infections result from perioperative contamination, almost a half of AGI occur between 25-70 months following the open or endovascular reconstruction. The described longest interval between primary reconstruction and AGI was 20 years $(12,13)$.

The most commonly isolated microorganisms in AGIs are gram-positive cocci. Staphylococcus aureus is isolated in 38-40 \% of cases (coagulase-negative staphylococci in $15 \%$ ), followed by Streptococci, Enterococci and gram-negatives organisms, namely in 25-36 \% of cases with Pseudomonas, Escherichia coli, and Bacteroides being the most common. Fungal infections caused especially by Candida species are rare but important pathogenetic factors of AGI. The increase in methicillin-resistant Staphylococcus aureus (MRSA) has become a problem rising in the past few years $(14,15)$.

\section{Diagnosis}

The diagnosis is based on clinical symptomatology, laboratory markers, microbial cultures, and imaging modalities.

Clinical manifestation of AGI is different and depends especially on the severity of infection. Low-grade infections are caused by low-virulence microorganisms, come usually later after the vascular reconstruction and their symptoms are vague and non-specific, thus resulting in a delay to the diagnosis (malaise, weakness, weight loss). High-grade infections are caused by high-virulence bacteria, where sepsis, fever, abdominal and back pains are the main symptoms. False aneurysm, graft thrombosis, groin swelling, erythema, wound fistula, pain, or hematemesis in cases of AEF are other very important signs of AGI caused by highly virulent organisms (16). AEF was first described by Brock in 1953 and was successfully treated by Herber in 1957. AEF causes one third of endograft infections and is the most challenging problem for vascular surgeons. The bleeding is usually the first warning sign heralding the massive hemorrhage which follows after hours, days or even weeks $(17,18)$. Laboratory markers such as leukocytosis, elevated CRP levels, and positive blood cultures may be helpful, but are neither sensitive nor specific. Fiorani reported the mean interval of 42 days (2-392 days) between the onset of symptoms and diagnosis of AGI (19). 


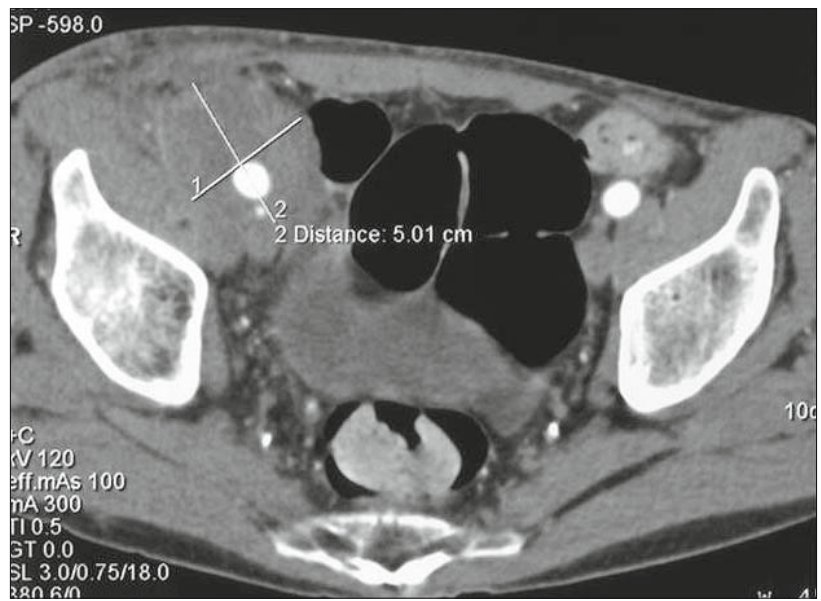

Fig. 1. Fluid collections surrounding the right leg of aortobifemoral graft (MDCT).

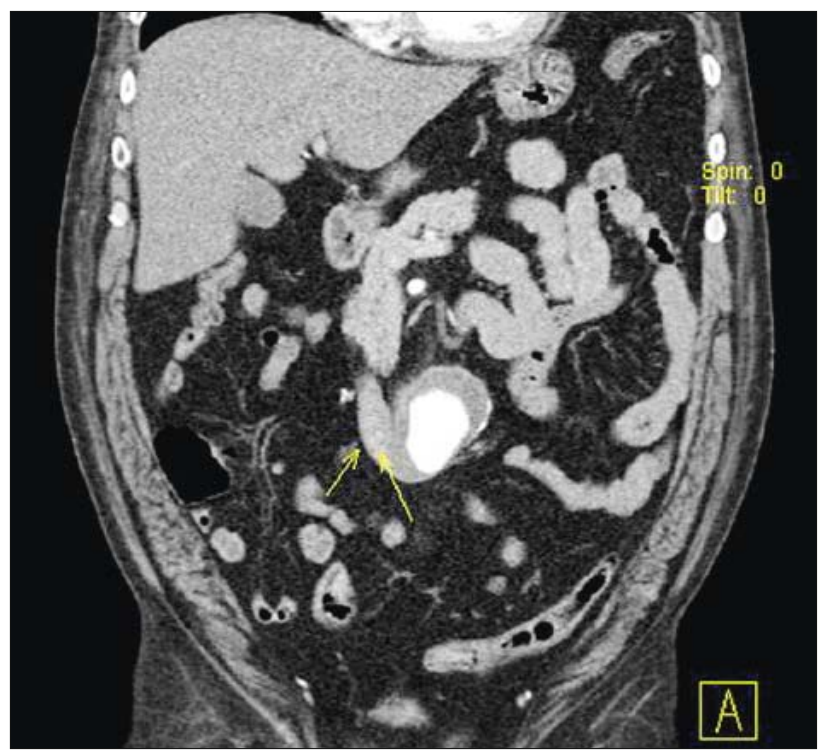

Fig. 2. Focal bowel thickening with direct contrast enhancement of the bowel wall (MDCT).

Blood and wound samples collected from the field of vascular graft infection can be negative in more than $30 \%$ of cases in spite of clearly manifesting AGI.

Current imaging modalities to diagnose AGI include duplex ultrasound (DUS), multidetector computed tomography (MDCT), magnetic resonance imaging (MRI), fluorodeoxyglucose-positron emission computed tomography (FDG-PET CT), leukocyte scintigraphy, and single positron emission computer tomography (SPECT) $(20,21)$.

DUS is a less invasive, operator-dependent imaging modality which can detect pseudoaneurysm, gas surrounding vascular prosthesis, and fluid collection and can distinguish hematoma from abscess formation mainly in the groin. In case of central AGI, the diagnostic value is limited by the overlaying bowel gas and the diagnostic problem is also enhanced by obesity. The sensitivity and specificity of DUS is low and DUS is rarely useful for the diagnosis of AGI (22).
Angio-CT scan has some characteristic features for AGI: perigraft air, fluid, pseudoaneurysm, focal bowel thickening with signs of inflammation in the area of aortic graft (Fig. 1). Perigraft fluid, gas and inflammation can be observed more than three months after surgery. The persistence of gas around the graft beyond four weeks postoperatively and an increase in perigraft fluid collection size are suspicious of aortic graft infection. Pseudoaneurysm occurs in approximately one-quarter of vascular prosthetic graft infections, but the majority of patients with pseudoaneurysm have no AGI. In AGI, the interval of pseudoaneurysm formation is usually shorter than that in non-infected cases. Focal bowel thickening with direct contrast enhancement of the bowel wall (Fig. 2) is suspicious of AEF formation. The sensitivity and specificity of MDCT in advanced AGI approach $100 \%$, but in low-grade infections the sensitivity is only $55 \%$. An advantage of MDCT is the possibility of fine-needle aspiration of perigraft fluid in case of AGI suspicion. MDCT is a very good method for the diagnosis of AGI in cases of fulminant, high-grade infection, but MDCT has difficulty in identifying AGI in cases of low-grade AGI. The problem of MDCT scan lies also in the difficulty in differentiating between normal postoperative changes and AGI in the first six weeks after operation as well as in relatively high radiation burden $(23,24)$.

MRI has the same problems as MDCT in the early postoperative period. MRI is better than MDCT in differentiation of small perigraft fluid collections and inflammatory changes. MRI exhibits a low-density signal during the $\mathrm{T} 1$ imaging and a hyperintensive signal in T2-weighted imaging. The finding of air or fluid around the graft is normal in the first two or three months after graft implantation. The advantage of MRI is that it is a non-invasive method. In general, MRI has a sensitivity and specificity rates comparable to those of MDCT in AGI diagnosis $(25,26)$.

A relatively new and very progressive diagnostic method in AGI is 18F-fluoro-2-deoxy-D-glucose (FDG) PET-CT. It is based on the uptake of radioactive-labeled glucose in metabolically active cells. Spacek (27) found an intense focal uptake by FDG-PET CT in $93 \%$ of prosthetic graft infections. In case of focal FDG uptake being absent, the prosthetic graft infection could be excluded in 97 $\%$ of the cases. Not only is this method able to show the presence of AGI, it also can show its extent. Our experience confirms the above mentioned results and we use FDG PET-CT as a standard diagnostic method in every case with suspicion of AGI (Fig. 3). A limitation of this method lies in the radiation exposure (28).

Leukocyte scintigraphy uses leukocyte radiolabeling techniques with ${ }^{111}$ Indium or ${ }^{99}$ Technetium. The reported sensitivity of this method is between $53 \%$ and $100 \%$. This method has recently been replaced by FDG PET-CT.

SPECT provides a three-dimensional image and improves sensitivity over planar imaging. It uses galium citrate, Ga-67, as tracer (29). Fused SPECT/CT images (30) can dramatically improve image interpretation by differentiating normal physiology from pathology. In spite of the fact that several case studies of SPECT/CT usage in the diagnosis of SSI have been published, we still have to wait for further investigations to be able to elucidate its role in the diagnosis of AGI. 


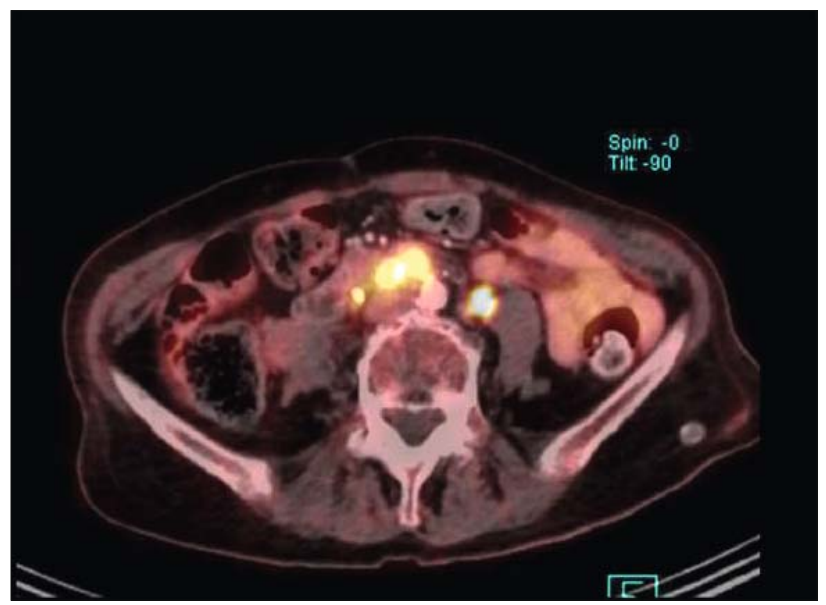

Fig. 3. Aortic graft infection (FDG-PET/CT).

Diagnostic radiological methods have a strong potential in the future perspectives. Preliminary data show the possible diagnostic value in bio-optical, bioluminescent imaging. The second method which could be used as a diagnostic tool of vascular graft infection is fluorescence, which is based on specific probes with attached fluorophores acting as reporters on infection or inflammation. Also some new nuclear diagnostic developments, for example ${ }^{18} \mathrm{~F}$-folate, ${ }^{18} \mathrm{~F}$ choline, galium-68, etc., can be used in PET or SPECT imaging (31, 32). Finally Gao (33) described laparoscopy as a diagnostic tool for the detection of AGI in a porcine model with the ability to carry out bacteriological sampling and local antibiotic treatment. However the above mentioned new methods need further clinical evaluation.

\section{Treatment options}

The surgical treatment of AGI is challenging and involves a major intervention in patients who are often critically ill. The basic principles of surgical treatment involve debridement of infected periprosthetic tissues, possible excision of the infected graft and secondary revascularization.

Traditionally, axilobifemoral extraanatomical bypass (AxBF) used to be utilized (34). The original unilateral graft was introduced by Louw and Blaisdell in 1963. Sauvage and Wood modified it to AxBF in 1966. AxBF used to be the gold standard reconstruction in AGI for many years. Achilles' heel of AxBF has high mortality rate, namely $25-40 \%$, aortic stump blow-out occurs with mortality rate over $30 \%$, graft thrombosis and poor long-term patency, and high reinfection rate between $5-15 \%(35,36,37)$. The introduction of externally supported grafts improved significantly the patency rate. Bacourt and Koskas (38) reported $9 \%$ occlusion rate for externally supported grafts compared with $22 \%$ for non-externally supported grafts at a median follow-up of 36 months. We have two possibilities of how to use the AxBF reconstructions, namely as staged or as simultaneous procedures. Each procedure has both advantages and disadvantages. The advantage of simultaneous reconstructions lies in one operating time, treatment of AGI and blood flow reconstruction. But this procedure increases the operating time, ischemic period, and metabolic stress for the patient. If the $\mathrm{AxBF}$ is performed a couple of days before aortic graft excision, this procedure reduces operative stress, limits hemodynamic consequences, decreases lower limb ischemia, but increases the risk for bacterial contamination of AxBF graft. The competitive flow between the EAB and original graft still exists, but it has never been practically reported to be the problem of graft occlusion. Due to the high mortality rate from aortic stump blow-out, the proper radical removal of all infected tissue is essential while the reinforcement of the aortic stump with the paravertebral fascia or omental wrap is also important. The choice of graft material used for AxBF reconstruction is important for the incidence of reinfection. Dacron grafts have the highest reinfection rates (15\%), PTFE grafts are burdened with $6 \%$ of reinfections, rifampicin-coated, or silver grafts have 4-10\% reinfections, while cryopreserved or fresh allografts have $3 \%$ reinfections and autogenous vein grafts are associated with the lowest infection rates approaching $0 \%$ (39).

Due to high mortality and morbidity rates, the AxBFs reconstructions have been steadily replaced during the last decade by in situ reconstructions. O'Connor in a meta-analysis (39) found that in situ reconstructions with graft excision, debridement of surrounding tissues and use of sartorius or gracilis muscles wrap as adjunct procedure in the groin are superior to $\mathrm{EAB}$ when considering perioperative mortality, amputation and reinfection rates (40, 41).

We have several optional graft materials to be chosen from. namely from fresh or cryopreserved arterial allografts, veins, rifampicin-soaked or silver-coated grafts, Dacron or PTFE grafts and endografts.

Arterial allografts have been used for the first time by Hopfner to replace a carotid artery of dog in 1903, Alexis Carrel used allografts in an experiment in 1908; in 1948 Gross treated aortic coarctation by interposition of arterial allograft and in 1952 Dubost replaced infrarenal aorta with a fresh aortic allograft. Technical ease of insertion, resistence to infection, freedom from anticoagulation and antibiotics use after 3-6 months are the advantages of allografts $(42,43)$. We can use two types of allografts - fresh or cryopreserved. A major drawback of cryopreserved allografts is the risk of degeneration leading to calcification, dilatation, or

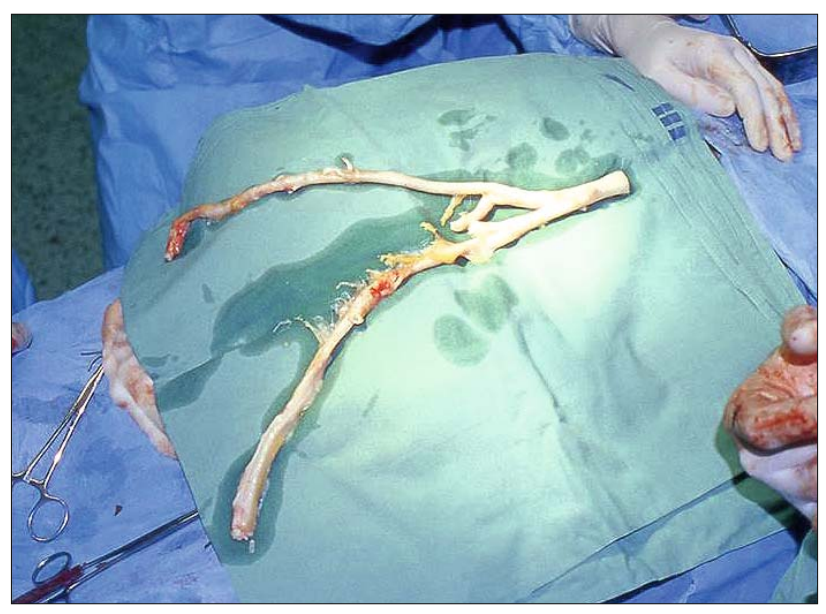

Fig. 4. Use of fresh arterial allograft for in situ replacement of bifurcated graft infection. 
even rupture. Kieffer (44) referred that the use of cryopreserved allograft is of particular benefit in patients with AEF reducing the one-year mortality rate from $34 \%$ with the use of conventional grafts to $9 \%$. The major problem of the use of allografts is their shortage especially in hospitals without allograft banks, as well as in hospitals not involved in transplantation program. Venous allografts are also resistant to infection, but are less durable than arterial allografts. There is still a debate whether to use immunosuppressive therapy postoperatively $(45,46)$. Due to antigenicity of fresh allografts and residual antigenicity of cryopreserved allografts we recommend low-dose cyclosporin. At present, cryopreserved allografts are used as a bridge temporizing procedure to help eradicate infection with subsequent prosthetic reconstruction. Some transplant centers including ours use fresh allografts (Fig. 4) with very good results. However some authors draw attention to their dilatation over long-term period after implantation.

Another material modality is the use of patient's superficial femoral vein as so-called Neoaortoiliac System (NAIS) (47). The advantage of NAIS is in its resistance to reinfection characterized by low recurrent infection ( $<2 \%$ ), long-term durability with fiveyear primary patency and limb salvage between 75 and $91 \%$, or 89-96 \%, short-term antibiotic and antithrombotic therapies and low cost. The disadvantage lies in extended surgical trauma and time-consuming procedure. Venous DUS is required to determine the suitability of the conduit. Femoral veins with diameter smaller than $6 \mathrm{~mm}$ or those with evidence of chronic occlusion should not to be used. The use of intermittent pneumatic compression and low-molecular heparin application to prevent deep venous thrombosis is useful after reconstruction. Standard anticoagulation or antiaggregation therapy is important for prevention of deep venous thrombosis. Venous morbidity is low with only $15 \%$ of patients experiencing chronic venous insufficiency at five years $(48,49)$.

Antibiotic-impregnated and silver-coated grafts are often used for in situ aortic reconstruction after AGI. In 1987, Walker (50) reported the first cases of in situ repair of AGI by replacing the infected grafts with Dacron grafts. The results of this method were very bad with more than $25 \%$ mortality rate and more than $30 \%$ reinfection rate. Investigation continued with local administration of gentamicin at the grafts. But local effective antimicrobial gentamicin concentration lasted only two to three days above the minimum inhibitory concentration. Irrigation of the new grafts with antiseptic solution was the next attempt in the treatment of AGI. In spite of this procedure being successful with one-year survival at $80 \%$, the technique was very complicated and required multiple catheters for irrigation. PTFE grafts soaked in oxacillin were the next attempt, but they had very short antibacterial activity, namely up to 10 days. The new base in the development of antibiotic-impregnated grafts was placed in 1969 in Prague by Krajicek (51). It was discovered that collagen and antibiotic impregnation using neomycin and chlortetracyclin of Dacron grafts was very effective in replacing the infected aortic grafts in dogs. The research continued in the United States by Moore (52) in animal experiments using amikacin and collagen impregnation of Dacron grafts. Various antibiotics were used but finally rifampicin was proved to work better than other antibiotics due to its very good binding to
Dacron ability and considerable anti-staphylococcal activity, but its efficacy against Gram-negative microorganisms is low. Rifampicin-bound Dacron grafts used after extirpation of AGI and proper debridement of surrounding tissue showed significant decrease in the re-infection rate. Rifampicin-Bonded Graft European Trial, a multicenter, prospective, randomised trial with 2610 randomized patients between 1991 and 1993 and Italian study with 600 patients found no significance in the use of rifampin-soaked Dacron grafts for prophylaxis of AGI. Rifampicin-soaked Dacron grafts used in in situ reconstruction together with omental wrapping and longterm antibiotics achieved successful outcomes in various studies in Mayo clinic, University of South Florida etc. $(53,54)$. In the future, we can expect rifampin-soaked Dacron grafts to become limited due to the increasing prevalence of virulent organism resistant to rifampicin, e.g. MRSA. Therefore, further research into bonding of other antibiotics may have to be considered.

Silver-coated vascular prostheses are based on the release of substantial amounts of bactericidal silver into the surrounding tissue. Two types of silver-coated vascular prostheses have been introduced in clinical practice. Silver acetate-coated polyester grafts rapidly release substantial amounts of silver into the surrounding tissue in the interval of $2-3$ weeks after implantation. Vaporized metallic silver-coated polyester graft releases marginal amounts of silver in the perigraft tissue during the first 12 months after implantation $(55,56)$. The advantage of silver acetate-coated grafts in comparison with the second type of grafts lies in better perigraft vascularization and reduced perigraft inflammation during the first 14 days after implantation and it should be the reason of lower reinfection rate. The comparison of rifampin-impregnated and silver-coated vascular prostheses does not give convincing results in terms of better efficiency in one or other type of vascular prosthesis in the treatment of AGI. Their advantage lies in the immediate availability but we have to count with higher number of re-infection rates ranging from 4 to $22 \%(57,58,59)$.

The optimal management of endograft infections is a more complicated issue. Setacci (60) evaluated the outcomes of endograft infection after EVAR. The overall in-hospital mortality rate was $30 \%$. Graft excision with EAB or in situ reconstruction was burdened by $16 \%$ or $6 \%$ mortality rates, respectively. Recently the in situ reconstruction is used more often because it is burdened by lower reinfection rate, hemorrhage, thrombosis, and pseudoaneurysm formation in comparison with EAB. However the role of EAB is still important in severe purulent infections.

The basic treatment of aortic endograft infections is endograft explantation with debridement of infected tissues and replacement by vascular graft during open surgery. Explantation of infected grafts is a very demanding procedure especially in cases where infected endografts involve visceral and renal arteries or have suprarenal barb fixation. In specific cases, the proximal bare stent had to be left in place or proximal dislodgement of stent-graft had to be used with gently squeezing the upper stent and pushing hooks or barbs in proximal direction to facilitate graft explantation $(61,62)$. Vascular clamps are placed in subdiaphragmatic portion of aorta. In high-risk patients we can use stage procedure with AxBF bypass first to reduce cardiac afterload. In general, the 
surgical approach should be reserved for young patients in good health condition and long-term life expectation $(63,64,65,66)$.

Preservation of AGI is another treatment option $(67,68)$ which can be used as a method of choice in patients suffering from severe comorbidities. Cernohorsky (69) found no difference in the mortality rate of conservative versus surgical forms of therapy in low-grade infections in a small case retrospective study. But Ducasse (70) reported $36.4 \%$ mortality rate for EVAR infections managed conservatively versus $14 \%$ for those managed surgically. Other authors referred higher mortality rates approaching $45 \%$ during the first 12 months (71). Belair (72) gave evidence of lower mortality in patients who in addition to antibiotic treatment also underwent procedures such as CT-guided percutaneous drainage, or surgical debridement, sac irrigation with povidone-iodine or antibiotics for weeks and omentoplasty with long-term antibiotic therapy. Moulakakis (73) stated that conservative treatment has the poorest results and should be reserved only for selected patients. According to recent knowledge, the preservation of infected EVAR should be reserved only for patients who are poor candidates for major aortic procedure due to comorbidities or anatomic location of graft. Contraindication to conservative treatment of AGI is valid in cases of anastomotic aneurysm, suture line hemorrhage, systemic sepsis, AEF and aggressive bacterial infection (e.g. Pseudomonas, MRSA, or Salmonella).

Oliva and Desphande $(74,75)$ were the first to use endograft successfully in the treatment of AEF in the late 1990s. But several reports later described contradictory outcomes with the development of recurrent hemorrhage or persistent infection in more than $40 \%$ of the patients and mortality rate in more than $30 \%$ of cases $(76,77)$. These data support the strategy of using endovascular repair only as a bridge option allowing definitive repair at a later time after optimization of the patient's condition.

The use of VAC system for Szilagyi III type of infections (78, 79 ) in conjunction with open debridement is a useful procedure for eradication of prosthetic infection in the groin. VAC reduces bacterial colonization, promotes granulation, decreases edema, and stimulates microvascularization in the wound. VAC can be directly applied without a special plastic foil on the infected grafts with continuous topical negative pressure starting at 50-75 mmHg and continued at 50-125 mmHg. Dressing changes are carried out according to clinical presentation, usually every three to five days. Dosluoglu (80) reported graft salvage rates of $90 \%$ using VAC system. A novel hybrid technique (EndoVAC) combining the use of stent-grafts, surgical debridement, and VAC has been recently reported as a promising option in selected patients (81). This technique can be used in groin infections, enables radical debridement of infected tissues in the surrounding of graft anastomosis and minimizes serious bleeding from anastomosis. After eradication of infection, the primary graft together with endograft are excised and replaced with AxBF or in situ reconstruction. The main problem of this novel technique is in a quite high number of reinfections especially when used in high-grade infections.

Antibiotic use in vascular surgery has a significant benefit in reduction of SSI. In cases of AGI, antibiotics play a very important role. At the beginning of AGI diagnosis, broad-spectrum antibiotics are used while culture-specific antibiotics are used in the later period of treatment (82). The duration of antimicrobial treatment in patients with AGI after the removal of infected graft is controversial. No current guidelines exist. Some authors recommend lifelong antibiotic treatment, some six months, some six weeks. According to our experience, we recommend to use antibiotics for a no shorter period than six weeks after radical surgery and to terminate the antibiotic treatment in cases where there are no clinical, radiological (especially PET CT) and laboratory (CRP) signs of infection.

\section{Future treatment perspectives}

AGI is a serious and in many cases a devastating problem with high risk of mortality, amputation, and reinfection. AGI significantly burdens the healthcare system. Surgery with long-term antimicrobial therapy has the key role in the treatment of AGI. Nevertheless, the role of radical surgery is waiting to be defined. Many patients indicated for primary endovascular procedure suffer from severe comorbidities and are unfit for open surgery. At the time of AGI we have to balance the operative risk, patient's profit, and life expectancy. The personalized approach or case-by-case approach is mandatory. In the near future we will have to solve more endograft infections due to the growing number of endovascular procedures and aging population. We still have no well-defined guidelines for graft and endograft infections treatment. Many issues in the diagnosis and especially in the treatment of AGI have to be solved. Therefore, in order to create the guidelines we need more multicentric studies and meta-analyses in the field as important as is the vascular and endovascular surgery associated with AGI.

\section{References}

1. de Donato G, Setacci F, Galzerano G, Ruzzi U, Borrelli M, Mazzitelli G, Setaccu C. Prosthesis infection: prevention and treatment. J Cardiovasc Surg 2014; 55: 779-792.

2. Young MH, Upchurch RB Jr, Malani PN. Vascular Graft Infections. Infect Dis Clin N Am 2012; 26: 41-56.

3. Swain TW, Calligaro KD, Dougherty MD. Management of infected aortic prosthetic grafts. Vasc Endovascular Surg 2004; 38: 75-82.

4. Hulin SJ, Morris GE. Aortic endograft infection: open surgical management with endograft preservation.Eur J Vasc Endovasc Surg 2007; 34 : 191-193.

5. Hasse B, Husmann I, Zinkernagel A, Weber R, Lachat M, Mayer D. Vascular graft infections. Swiss Med Wkly 2013; 143:w13754.

6. Lyons OT, Patel AS, Saha P, Clough RE, Price N, Taylor PR. A 14year experience with aortic endograft infection: management and results. Eur J Vasc Endovasc Surg 2013; 46: 306-313.

7. Almeida CEPC, Reis L, Carvalho L, Almeida CMC. Collagen implant with gentamicin sulphate reduces surgical site infection in vascular surgery: A prospective cohort study. Int J Surg 2014; 12: 1100-1104.

8. Stewart AH, Eyers PS, Earnshaw JJ. Prevention of infection in peripheral arterial reconstruction: a systematic review and metaanalysis. J Vasc Surg 2007; 46: 148-155.

9. Szilagyi DE, Smith RF, Elliott JP, Vrandecic MP. Infection in arterial reconstruction with synthetic grafts. Am Surg 1972; 176: 321-333.

10. Herscu G, Wilson SE. Prosthetic infection: lessons from treatment of the infected vascular graft. Surg Clin North Am 2009; 89: 391-401. 
11. Goldstone J, Moore WS. Infection in vascular prostheses: clinical manifestations and surgical management. Am J Surg 1974; 128: 225-233.

12. Swain TW, Calligaro KD, Dougherty MD. Management of infected aortic prosthetic grafts. Vasc Endovascular Surg 2004; 38: 75-82.

13. Erb S, Sidler JA, Elzi L, Gurke L, Battegay M, Widmer AF, Weisser M. Surgical and Antimicrobial Treatment of Prosthetic Vascular Graft Infections at Different Surgical Sites: A Retrospective Study of Treatment Outcomes. PLoS One 2014; 9: e 112947.

14. Aboshady I, Raad I, Shah AS, Vela D, Dvorak T. A pilot study of a triple antimicrobial-bonded Dacron graft fro the prevention of aortic graft infection. J Vasc Surg 2007; 46: 148-155.

15. Maze MJ, Laws P, Buckenham T, Pithie A, Gallagher K. Outcomes of infected abdominal aortic grafts managed with antimicrobial therapy and graft retention in an unselected cohort. Eur J Endovasc Surg 2013; 45: 373-380.

16. Ziaja D, Biolik G, Chudek J, Ziaja K. Purulent Cutaneous Fistula: As the First Symptom of the Late Aortic Stent-Graft Infection - A Case Report and Review of the Literature. Case Rep Surg 2013; 5: 1-4.

17. Zaki M, Tawfick W, Alawy M, ElKassaby M, Hynes N, Sultan S. Secondary aortoduodenal fistula following andovascular repair of inflammatory abdominal aortic aneurysm due to Streptococcus anginosus infection: A case report and literature review. Int J Surg Case Rep 2014; 5: 710-713.

18. Solomon B, Billy K, Caron R, Veith FJ, Jacobowitz G. Aortic endograft infection with aortoduodenal fistula associated with adjacent vertebral body mycobacterial osteomyelitis (Pott's disease). Ann Vasc Surg 2012; 26: 276. Ele 276.e4.

19. Fiorani P, Speziale F, Calisti A, Misuraca M, Zaccagnini D, Rizzo L, Giannoni MF. Endovascular graft infection: preliminary results of an international enquiry. J Endovasc Ther 2003;10: 919-927.

20. Bruggink JLM, Slart RHJA, Pol JA, Reijnen MMPJ, Zeebregts CJ. Current Role of Imaging in Diagnosing Aortic Graft Infections. Sem Vasc Surg 2011; 24: 182-190.

21. Macedo TA, Stanson AW, Oderich GS. Infected aortic aneurysm: imaging findings. Radiology 2004; 231: 250-257.

22. Valentine RJ. Diagnosis and management of aortic graft infection. Semin Vasc Surg 2001; 14: 292-301.

23. Harris KA, Kozak R, Caroll SE. Confirmation of infection of an aortic graft. J Cardiovasc Surg (Torino) 1989; 30: 230-232.

24. Bunt TJ. Vascular graft infections: an update. Cardiovasc Surg 2001: 9: 225- 233.

25. Spartera C, Morettini G, Petrassi C. Role of magnetic resonance imaging in the evaluation of aortic graft healing, perigraft fluid collection, and graft infection. Eur J Vasc Surg 1990; 4: 69-73.

26. Shahidi S, Eskil A, Lundof E. Detection of abdominal aortic graft infection: comparison of magnetic resonance imaging and indium-labeled white blood cell scanning. Ann Vasc Surg 2007; 21: 586-592.

27. Spacek M, Belohlavek O, Votrubova J. Diagnostics of "none-acute" vascular prosthesis infection using 18F-FDG PET/CT: our experience with 96 prostheses. Eur J Nucl Med Mol Imaging 2009; 36: 850-858.

28. Bruggink JL, Glaudemans AW, Saleem BR. Accuracy of FDG-PETCT in the diagnostic work-up of vascular prosthetic graft infection. Eur J Vasc Endovasc Surg 2010; 40: 348-354.

29. Yamamoto Y, Nishiyama Y, Monden T. Clinical usefulness of fusion of 1311 SPECT and CT images in patients with differentiated thyroid carcinoma. J Nucl Med 2003; 44: 1905-1910.
30. Petruzzi N, Shanthly N, Thakur M. Recent trends in soft-tissue infection imaging. Semin Nucl Med 2009; 39: 115-123.

31. Signore A, Chianelli M, DÁlessandria C. Receptor targeting agents for imaging inflammation/infection: where are we now? Q J Nucl Med Mol Imaging 2004; 50: 236-242.

32. Ketai L, Hartshorne M. Potential uses of computed tomography SPECT and computed tomography-coincidence fusion images of the chest. Clin Nucl Med 2001; 26: 433-41.

33. Gao H, Lund L, Prag J. Laparoscopic diagnosis and treatment of aortic vascular prosthetic graft infection in a porcine model. Eur J Vasc Endovasc Surg 2008; 35: 41-45.

34. Berger P, Moll F. Aortic Graft infections: Is There Still a Role for Axillobifemoral Reconstruction? Semin Vasc Surg 2011; 24: 205-210.

35. Reilly L. Aortic graft infection: evolution in management. Cardiovasc Surg 2002; 10: 372-377.

36. O'Connor S, Andrew P, Batt M. A systematic review and metaanalysis of treatments for aortic graft infection. J Vasc Surg 2006; 44: 38-45.

37. Brown KE, Heyer K, Rodriguez H. Arterial reconstruction with cryopreservad human allografts in the setting of infection: a single-center experience with midterm follow-up. J Vasc Surg 2009; 49: 660-666.

38. Bacourt F, Koskas F. Axillobifemoral bypass and aortic exclusion for vascular septic lesions: a multicenter retrospective study of 98 cases. French University Association for Research in Surgery. Ann Vasc Surg 1992; 6:119-126.

39. O'Connor S, Andrew P, Batt M, Becquemin JP. A systemic review and meta-analysis of treatments for aortic graft infection. J Vasc Surg 2006; 44: 38-45.

40. Treska V., Certik B., Molacek J., Houdek K., Cechura M., Sulc R., Fichtl J., Dolezal J., Polak M. Vascular graft infections in aortofemoral region. Perspect Surg 2012; 91: 597-600.

41. Touma J, Cochennec F, Parisot J, Fialaire Legendre A, Becquemin JP, Desgranges P. In situ reconstruction in native and prosthetic aortic infections using cryopreserved arterial allografts. Eur J Vasc Endovasc Surg 2014; 48: 292-299.

42. Pejkic S, Jakovljevic N, Kuzmanovic I, Markovic M, Cvetkovic S, Cinara I, Kostic D, Maksimovic Z, Davidovic L. In situ replacement of infected vascular prosthesis with fresh arterial homograft: early and longterm results in 18 patients. Srp Arh Celok Lek 2013; 141: 750-757.

43. Diener H, Hellwinklel O, Carpenter S, Larena-Avellaneda A, Debus ES. Homografts and extra-anatomical reconstructions for infected vascular grafts. J Cardiovasc Surg 2014; 55 (Suppl 1 to No 2): 217-223.

44. Kieffer E, Gomes D, Chiche L. Allograft replacement for infrarenal aortic graft infection: early and late results in 179 patients. J Vasc Surg 2004; 39: 1009-1017.

45. Harlander-Locke MP, Harmon LK, Lawrence PF, Oderich GS, McCready RA, Morasch MD, Feezor RJ. The use of cryopreserved aortoiliac allograft for aortic reconstruction in the United States. J Vasc Surg 2014; 59: 669-674.

46. Vogt PR. Arterial Allografts in Treating Aortic Graft Infections: Something Old, Something New. SWemin Vasc Surg 2011; 24: 227-233.

47. Chung J, Clagett PG. Neoaortoiliac System (NAIS) Procedur efor the Treatment of the Infected Aortic Graft. Semin Vasc Surg 2011; 24: 220-226.

48. Ali AT, Modrall JG, Hocking J, Valentine RJ, Spencer H, Eidt JF, Clagett GP. Long-term results of the treatment of aortic graft infection by in situ replacement with femoral popliteal vein grafts. J Vasc Surg 2009; 50: 30-39. 
49. Bell CL, Ali AT, Brawley JG, D’Addio VJ, Modrall JG, Valentine RJ, Clagett GP. Arterial reconstruction of infected femoral artery pseudoaneurysms using superficial femoral-popliteal vein. J Am Coll Surg 2005; 200: 831-836.

50. Walker WE, Cooley DA, Duncan JM. The management of aortoduodenal fistula by in situ replacement of the infected abdominal aortic graft. Ann Surg 1987; 205: 727-732.

51. Krajicek M, Dvorak J, Chvapil M. Infection-resistant synthetic vascular substitutes. J Cardiovasc Surg (Torino) 1969; 10: 453-457.

52. Moore WS,Chvapil M, Seiffert G. Development of an infection-resistant vascular prosthesis. Arch Surg 1981; 116: 1403-1407.

53. Lew W., Moore W. Antibiotic-Impregnated Grafts for Aortic Reconstruction. Semin Vasc Surg 2011; 24: 211-219.

54. Goëau-Brissonniere O1, Mercier F, Nicolas MH, Bacourt F, Coggia M, Lebrault C, Pechere JC. Treatment of vascular graft infection by in situ replacement with a rifampin-bonded gelatin-sealed Dacron graft. J Vasc Surg 1994; 19: 739-741.

55. Jeanmonod P, Laschke MW, Gola N, von Heesen M, Glanemann M, Dold S, Menger MD, Moussavian MR. Silver acetate coating promotes early vascularization of Dacron vascular grafts without inducing host tissue inflammation. J Vasc Surg 2013; 58: 1637-1643.

56. Zegelman M, Guenther G, Waliszewski M, Pukacki F, Stanisic MG, Piquet P, Passon M, Halloul Z, Tautenhahn J, Claey L, Agostinho C, Simici D, Doebrich D, Mueller C, Balzer K. Results from the International Silver Graft Registry for high-risk patients treated with a metallic-silver impregnated vascular graft. Vascular 2013; 21: 137-147.

57. Delva JC, Deglise S, Bérard X, Dubuisson V, Delva F, Stecken L, Ducasse E, Midy D. In-situ revascularisation for secondary aorto-enteric fistulae: the success of silver-coated Dacron is closely linked to a suitable bowel repair. Eur J Vasc Endovasc Surg 2012; 44: 417-424.

58. Sousa JV, Antunes L, Mendes C, Marinho A, Goncalves A, Goncalves $\mathbf{O}$, Matos A. Prosthetic vascular graft infections: a center experience. Angiol Cir Vasc 2014; 10: 52-57.

59. Jeanmonod P, Laschke MW, Gola N, von Heesen M, Glanemann M, Menger MD, Moussavian MR. Early host tissue response to different types of vascular prostheses coated with silver acetate or vaporized metallic silver. Eur J Vasc Endovasc Surg 2014; 47: 680-688.

60. Setacci C, De Donato G, Setacci F, Chisci E, Perulli A, Galzerano G, Sirignano P. Management of abdominal endograft infection. J Cardiovasc Surg 2010; 51: 33-41.

61. Capoccia L, Mestres G, Riambau V. Current technology for the treatment of infection following abdominal aortic aneurysm (AAA) fixation by endovascular repair (EVAR). J Cardiovasc Surg 2014; 55: 381-389.

62. Herdrich BJ, Fairman RM. How to manage infected aortic endografts. J Cardiovasc Surg 2013; 54: 595-604.

63. Botsios S, Bausback Y, Piorkowski M, Werner M, Branzan D, Scheinert D, Schmidt A. Late open conversion after endovascular aneurysm repair. Interact Cardiovasc Thorac Surg 2014; 19: 622-626.

64. Fatima J, Duncan AA, de Grandis E, Oderich GS, Kalra M, Gloviczki P, Bower TC. Treatment strategies and outcomes in patients with infected aortic endografts. J Vasc Surg 2013; 58: 371-379.

65. Kalpa GP, Wong E, Devine T. Stent graft infection secondary to apendicitis: an unusual complication of endovascular abdominal aortic aneurysm repair. J Surg Case Rep 2014; 10: rju 108.
66. Gardner GP, Morris ME, Makamson B, Faizer RM. Infection of an aortic stent graft with suprarenal fixation. Ann Vasc Surg 2010; 24: 418.e1-6.

67. Treska V, Houdek K, Vachtova M, Smid D, Kormunda S. Management of the prosthetic vascular graft infections - the influence of predictive factors on treatment results. Bratislava Medical Journal. 2008; 109: 544-550.

68. Lawrence PF. Conservative Treatment of Aortic Graft Infection. Semin Vasc Surg 2011; 24: 199-204.

69. Cernohorsky P, Reijnen MM, Tielliu IF, van Sterkenburg SM, van den Dungen JJ, Zeebregts CJ. The relevance of aortic endograft prosthetic infection. J Vasc Surg 2011; 54: 327-333.

70. Ducasse E, Calisti A, Speziale F, Rizzo L, Misuraca M, Fiorani P. Aortoiliac stent graft infection: current problems and management. Ann Vasc Surg 2004; 18: 521-526.

71. Lyons OT, Patel AS, Saha P. A 14-year experience with aortic andograft infection: management and results. Eur J Vasc Endovasc Surg 2013; 6: 306-313.

72. Belair M, Soulez G, Oliva VL. Aortic graft infection: the value of percutaneous drainage. AJR Am J Roentgenol 1998; 171: 119-124.

73. Moulakakis KG, Sfyroeras GS, Mylonas SN, Mantas G, Papapetrou A, Antonopoulos CN, Kakisis JD, Liapis CD. Outcome after preservation of infected abdominal aortic endografts. J Endovasc Ther 2014; 21: 448-455.

74. Oliva VL, Bui BT, Leclerc G, Gravel D, Normandin D, Prenovault J, Guimond JG. Aortoesophageal fistula: repair with transluminal placement of a thoracic aortic stent-graft. J Vasc Interv Radiol 1997; 8: 35-38.

75. Deshpande A, Lovelock M, Mossop P, Denton M, Vidovich J, Gurry J. Endovascular repair of an aortoenteric fistula in a high-risk patient. J Endovasc Surg 1999; 6: 379-384.

76. Setacci C, de Donato G, Setacci F. Endografts for the treatment of aortic infection. Semin Vasc Surg 2011; 24: 242-249.

77. Kakkos SK, Antoniadis PN, Klonaris CN. Open or endovascular repair of aortoenteric fistulas? A multicentre comparative study. Eur J Vasc Endovasc Surg 2011; 41: 625-634.

78. Mayer D, Hasse B, Koelliker J, Enzler M, Veith FJ, Rancic Z, Lachat M. Long-term results of vascular graft and artery preserving treatment with negative pressure wound therapy in Szilagyi grade III infections justify a paradigm shift. Ann Surg 2011; 254: 754-759.

79. Saziye K, Afksendiyos K. The vacuum-assisted closure (V.A.C®) system for surgical site infection with involved vascular grafts. Vascular 2015; 23: $144-150$.

80. Dosluoglu HH, Schimpf DK, Schultz R, Cherr GS. Preservation of infected and exposed vascular grafts using vacuum assisted closure without muscle flap coverage. J Vasc Surg 2005; 42: 989-992.

81. Dryjski M, Dosluoglu HH. A New Approach to Treating Infected Vascular Reconstructions: The Hybrid EndoVAC Technique. J Endovasc Ther 2011; 18: 674-675.

82. Chiesa R, Astore D, Frigerio S, Garriboli L, Piccolo G, Castellano R, Scalamogna M, Odero A, Pirrelli S, Biasi G, Mingazzini P, Biglioli P, Polvani G, Guarino A, Agrifoglio G, Tori A, Spina G. Vascular prosthetic graft infection: epidemiology, bacteriology, pathogenesis and treatment. Acta Chir Belg 2002; 102: 238-247. 